\title{
Experimental Study and Effect on Recycled Fibers Blended with Rotor/OE Yarns for the Production of Handloom Fabrics and Their Properties
}

\author{
Dessalegn Awgichew (D), ${ }^{1}$ S. Sakthivel, ${ }^{1}$ Eshetu Solomon, ${ }^{1}$ Addisalem Bayu, ${ }^{1}$ Robel Legese, \\ Daniel Asfaw, ${ }^{1}$ Meseret Bogale, ${ }^{1}$ Alemu Aduna, ${ }^{1}$ and S. Senthil Kumar ${ }^{2}$ \\ ${ }^{1}$ Department of Textile Technology, Faculty of Textile and Apparel Fashion Technology, Ethiopian Technical University, \\ Addis Ababa 190310, Ethiopia \\ ${ }^{2}$ Department of Hand Loom and Textile Technology, Indian Institute of Handloom Technology, Salem, Tamil Nadu, India
}

Correspondence should be addressed to Dessalegn Awgichew; desayemaryam@gmail.com

Received 13 April 2021; Revised 7 June 2021; Accepted 23 July 2021; Published 15 August 2021

Academic Editor: Baozhong Sun

Copyright (c) 2021 Dessalegn Awgichew et al. This is an open access article distributed under the Creative Commons Attribution License, which permits unrestricted use, distribution, and reproduction in any medium, provided the original work is properly cited.

\begin{abstract}
The uses of recycled materials have gained massive importance in the textile sector and other application areas as the effects of reducing natural resources are felt worldwide. This study aimed to analyze the effects of recycled fiber usage on the properties of OE-rotor spun yarns and hand-woven fabrics produced from these yarns. For this purpose, OE-rotor yarns are produced at different proportion levels from virgin cotton and recycled fibers derived from knitted garment wastes at 25\%, 50\%, and 75\%, respectively. For a better assessment, properties of OE-rotor yarns that contain recycled fibers and 100\% virgin cotton OE-rotor yarns are compared. Physical, structural, and mechanical properties such as unevenness, imperfections, hairiness, breaking force, and elongation are analyzed by Uster Tester 5 SX, Uster Zweigle Hairiness Tester 5, and Uster Tensorapid 3. Plain and twill handwoven fabrics are produced from OE-rotor spun yarns. Effects of recycled fiber proportion on hand-woven fabric properties such as pilling, abrasion resistance, and air permeability were also evaluated. Results showed that the use of up to $75 \%$ of recycled fiber cotton blended yarns shows no statistically significant differences in yarn and fabric properties.
\end{abstract}

\section{Introduction}

In recent years, textile production and consumption have skyrocketed as a result of global population growth and improved living standards. Extreme production in the textile industry is partly driven by the idea of the fashion industry that consumers need a collection of new clothes for each season. This increases the exchange rate of products and the rate of fabric and waste production [1].The clothing industry is one of the most vital sectors in the manufacturing of customer goods. However, the textile industry is one of the most polluting industries. Not only production but also the use of textiles will also generate waste. Many measures have been taken to cut its negative impact on the environment. One of them is the reuse, reuse, and manufacturing process of textiles. The reuse of textiles improves environmental and economic conditions, reduces the demand for textile chemicals, reduces the demand for land and reduces energy consumption, and encourages manufacturing. Suppliers increase the amount of recycling wasted on new products. Sushma Rani and Zeba Jamal [2] reported the need for good waste management is due to rising costs and declining land acquisition and the depletion of natural resources. The purpose of this study was to analyze recycling garment waste fibers blended with virgin cotton for hand-woven practices [3]. The study by Khan et al. analyzed and stated that the proportional amount of virgin cotton with recycled fibers is the most influential cause on properties of blended OE-rotor spun yarns. According to the process, using $25 \%$ of recycled fiber does not affect the uniformity and appearance of rotor 
spun yarn. Based on their results, $15 \%$ and $25 \%$ recycled waste ratio does not change the most quality parameters of OE-rotor yarn [4]. A large number of products are from reclaimed fibers. Much of this fiber is respun into new yarns and manufactured to woven, knitted, or vitally reused for nonwoven production, upholstery materials, composite biomaterials, and others such as garment linings and insulation materials [5]. The hand-woven textiles are crafts made to communicate cultural values with objects [6]. The recycled fiber from garment wastes has fiber properties that are very essential for converting them into spun yarns and further to home furnishing applications. In this study, the recycled fibers are spun into yarns by an OE-rotor spinning machine, and then, yarn samples undergo different property tests. After analyzing the yarn properties, different fabric samples were developed by hand-waving processes using a handloom. Samples developed from handloom are then subjected to analysis for weaving fabric properties such as pilling, abrasion resistance, and air permeability. The main purpose of the research was to investigate the effects of the physical properties of recycling blended yarns and hand-woven fabrics for home furnishing applications. Evaluation of main physical and mechanical factors for home furnishing textiles include unevenness, hairiness, strength, elongation, abrasion resistance, pilling, and air permeability. Reclaimed fibers are from a secondary cycle of processing [7]. To obtain them, fabric-type or thread-type textile waste is mechanically broken down into fibers. Conventionally, the waste is pretreated by means of cutting or picking and then transported through a take-in unit, acting as a clamp, or a drum rotating at high speed. It should be aimed to breakdown the waste in question, so as to achieve a type of reclaimed fiber which is easy to characterize. In particular, it should be aimed to preserve fiber length as much as possible for the most final applications [8].

\section{Materials and Methods}

In this study, Ne 20/1 OE-rotor yarns were produced from $100 \%$ virgin cotton, $100 \%$ virgin cotton, and recycled fiber blends with $(75 \%-25 \%, 50 \%-50 \%$, and $25 \%-75 \%)$ blend ratios. Middle Awash cotton was used as virgin cotton, and recycled fibers were obtained from knitted garment wastes collected in Addis Ababa, Ethiopia. HVI values of Middle Awash cotton are given in Table 1 .

The results from Table 1 expressed that the virgin cotton fiber is a medium staple with high breaking strength and good finesse and average maturity. From this, it can easily be processed in an OE-rotor machine, blending it with short fibers reclaimed from garment wastes. The parameters of the highest interest are the degree of material breakdown and fiber length and the distribution of fiber lengths. The degree of material breakdown is descriptive of the spectrum of materials that results from the breaking-down process. It is defined as the proportions of fibers, threads, bits, and remains of fabric in a specimen of $3-10 \mathrm{~g}$ of the blend of reclaimed fibers, depending on the proportion of unopened pieces (by manual separation), in units of mass per cent. The proportion of fiber and thread can be added with virgin fiber where the material is processed by means of the handloom process in order to make handloom fabrics [9].
TABLE 1: HVI values of virgin cotton.

\begin{tabular}{lc}
\hline Property & Value \\
\hline Micronaire, mg/inch & 3.4 \\
Maturity & 0.78 \\
Length, mm & 27.12 \\
Uniformity, \% & 79 \\
Short fiber index & 8.0 \\
Strength, cN/tex & 30.1 \\
Elongation & 5.7 \\
\hline
\end{tabular}

Figures 1(a) and 1(b) show garment cutting wastes sorted by color. Figure 1(a) shows recycled fibers reclaimed from garment wastes. After that, Ne 0.12 slivers were produced after two draw frame passages. In OE-rotor yarn production, rotor and opening roller revolutions were 9500 and $8600 \mathrm{rpm}$, respectively. Reclaimed fibers of fabric waste are characterized by their fiber lengths as well as their high share in fiber particles from the carrier fabric (e.g., fibers made by slitting film) and in particles from the backing material [10]. This shows clearly whether the fiber is appropriate for making textile products. The major characteristics such as fiber length, uniformity ratio, micronaire value, and tenacity were evaluated. For fiber length, $2.5 \%$ and $50 \%$ span length was found out using HVI. According to American Society for Testing Material (ASTM) standard fiber length, the corresponding uniformity ratio and fineness of the fiber were measured. Tenacity of the fiber is evaluated by a stelometer.

Figures 2(a) and 2(b) show blending of reclaimed fibers with virgin cotton in a mini carding machine Figures 2 (c) and 2(d) show sliver and yarns produced from reclaimed blended fibers. The essential parameters under physical, structural, and mechanical properties of produced yarn were measured by using the Uster tester 4 SX, Uster Zweigle Hairiness Tester 5, Uster Tensorapid 3, and Lawson Hemphill CTT. After analyzing the properties of the OE-rotor yarn produced by blending $100 \%$ virgin cotton with recycled fibers, different handloom fabric designs ( $1 / 3$ twill and $1 * 1$ plain fabrics) were produced using the yarns from $100 \%$ virgin cotton with recycled fibers, for the warp yarn of the plied yarns from each sample are used for weft single yarns. The effect of this yarn on the woven fabric properties such as air permeability, abrasion resistance, and pilling were evaluated by using the $\mathrm{H}$. Heal Nu-Martindale Abrasion and Pilling Tester. After 5000 cycles, the weight loss in $\mathrm{mg}$ and change of thickness in $\mathrm{mm}$ of the test samples were calculated. For pilling tendency, test ISO $12945: 2$ method is used. In this method, the test specimens were determined by comparing with standard photographs. " 5 " rating means there is no visible change on the fabric surface after the test is carried out. The air permeability is measured by using $20 \mathrm{~cm}^{2}$ test areas and $100 \mathrm{~Pa}$ test pressure in accordance with ISO 9237.

\section{Results and Discussion}

Evaluation of yarn properties for a better understanding of how usage of recycled fiber effects on quality of OE-rotor spun yarns and properties such as unevenness, 

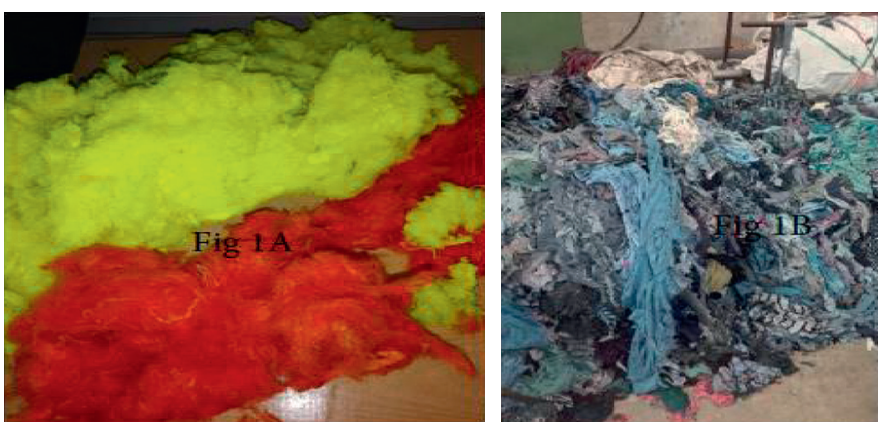

(a)
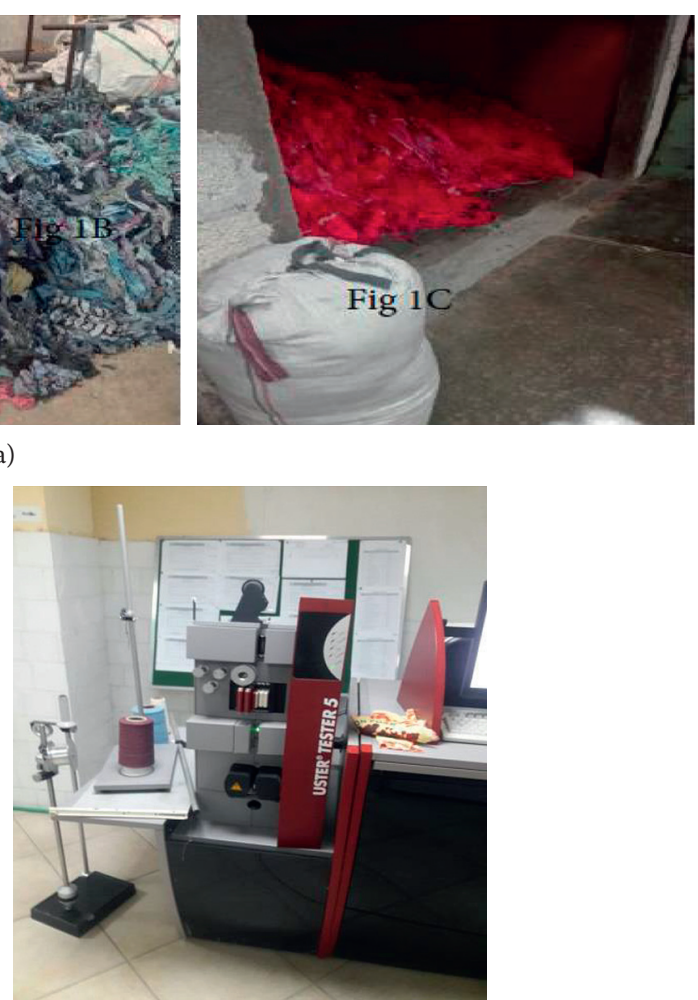

(b)

Figure 1: (a) Recycled fibers from garment waste. (b) Recycled fibers sorting, fiber, and yarn testing.
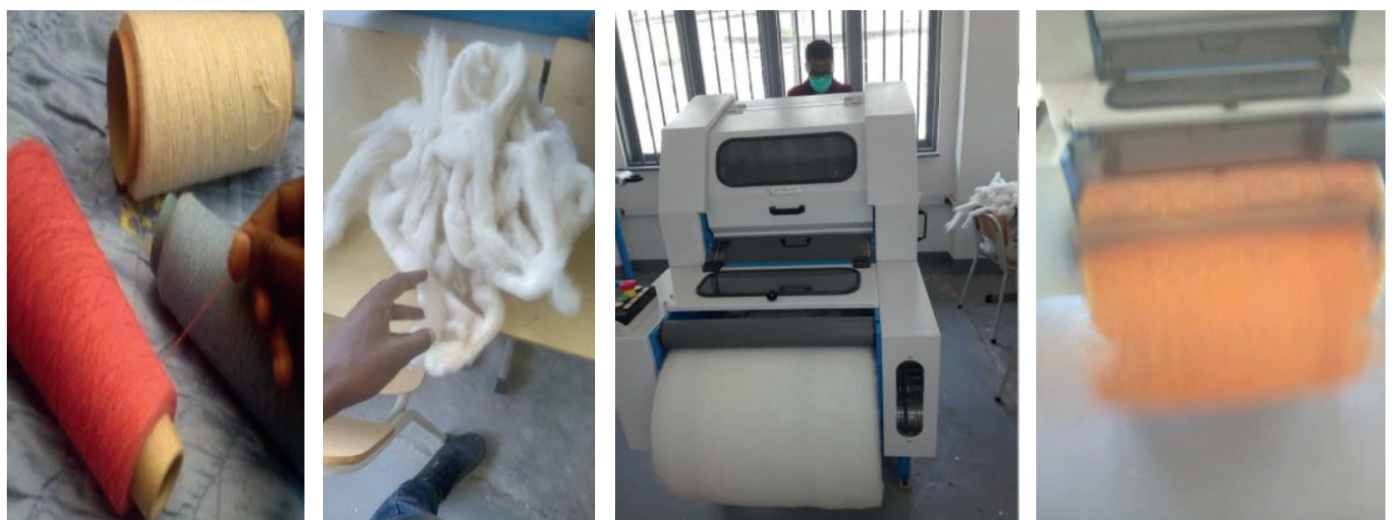

FIGURE 2: Blending recycled fibers in a mini carding machine and OE yarn from virgin cotton-recycled fiber blends.

imperfections, hairiness, breaking force, breaking elongation, statistically by using ANOVA, and confidence interval graphs at $95 \%$ confidence level. The same results were obtained by S. Sakthivel et al. and Ahmad Ashfaq [11, 12] (Table 2).

3.1. Effect of Unevenness. Figure 3 shows the effect of recycled fibers proportion on yarn unevenness. Unevenness and proportion of recycled fibers show parallel increase due to the increasing amount of short fiber in the yarn. However, there is no statistically significant difference between the blended yarns. Table 3 provides the ANOVA results and Table 4 provides the pairwise comparisons of the yarn types.
As it is indicated in Table 3, recycled fibers usage has no statistically significant difference on yarn unevenness ( $p=0.0743$ ). Moreover, according to the results from Table 4, the pairwise analysis of the yarn samples except for $100 \%$ VC with $25-75 \%$ VC-R, there is no statistically significant difference between other samples at $(p<0.05)$. The same findings were given by Richa Gupta and Chandanu. $\mathrm{R}$ $[13,14]$.

3.2. Effect of Hairiness. Figure 4 shows the appearance result of sample OE yarns made from $100 \%$ virgin cotton and recycled fiber blends tested. It illustrates that sample 1 (sa1) appearance values of the area are unit hyperbolic till the 
TABLe 2: Average yarn test results for samples.

\begin{tabular}{|c|c|c|c|c|c|c|c|}
\hline \multirow{2}{*}{ Samples } & \multirow{2}{*}{ Unevenness (\%) } & \multirow{2}{*}{ Hairiness index } & \multirow{2}{*}{$\begin{array}{l}\text { Strength } \\
(\mathrm{cN} / \text { tex })\end{array}$} & \multirow{2}{*}{ Elongation (\%) } & \multicolumn{3}{|c|}{ Imperfection } \\
\hline & & & & & $-50 \%$ thin place & $+50 \%$ thick place & +280 neps \\
\hline $100 \% \mathrm{VC}$ & 9.256 & 5.313 & 14.96 & 4.803 & 3.333 & 35.42 & 27.866 \\
\hline $75 \%-25 \% \mathrm{VC}-\mathrm{R}$ & 10.813 & 5.18 & 10.303 & 6.313 & 9.33 & 40.366 & 32.33 \\
\hline $50 \%-50 \%$ VC-R & 10.533 & 5.44 & 12.126 & 6.386 & 3.666 & 41.8 & 36.66 \\
\hline $25 \%-75 \% \mathrm{VC}-\mathrm{R}$ & 10.923 & 5.15 & 13.066 & 5.923 & 4.66 & 30 & 28 \\
\hline CV\% & $6.41 \%$ & $2.19 \%$ & $13.31 \%$ & $10.81 \%$ & $45.87 \%$ & $12.55 \%$ & $11.60 \%$ \\
\hline
\end{tabular}

VC, virgin cotton fiber; R, recycled fiber.

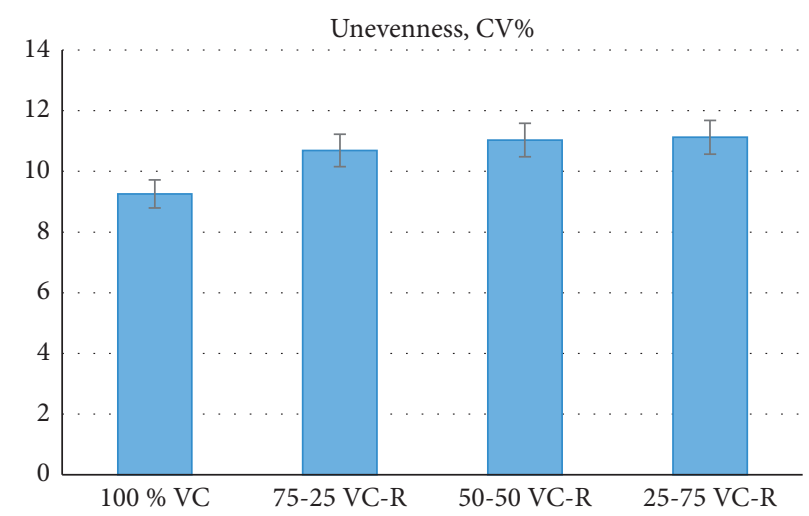

Figure 3: Unevenness (CVM \%) values and 95\% confidence intervals.

TABLE 3: ANOVA results for unevenness values.

\begin{tabular}{|c|c|c|c|c|c|c|}
\hline Source & & $\mathrm{DF}$ & Sum of squares & Mean square & $F$ value & $\operatorname{Pr}>F$ \\
\hline Model & & 3 & 6.65270000 & 2.21756667 & 3.24 & 0.0743 \\
\hline Error & & 9 & 6.15090000 & 0.68343333 & & \\
\hline Corrected total & & 12 & 12.80360000 & & & \\
\hline R-square: 0.519596 & Coefficient variance: 7.903444 & Roc & MSE: 0.826700 & Unevenness mean: 10.46000 & & \\
\hline
\end{tabular}

Dependent variable, unevenness.

TABLE 4: Pairwise comparison for unevenness (CVM \%) values.

\begin{tabular}{lcccccc}
\hline Raw & Raw materials & Mean difference & Standard error & Significance & Lower bound & Upper bound \\
\hline $100 \%$ VC & $25-75 \%$ VC-R & -1.1783 & 0.683433 & 0.785454 & -1.1470 & 1.6170 \\
& $50-50 \%$ VC-R & -1.7767 & 0.683433 & 0.345023 & -0.7400 & 2.1167 \\
& $75-25 \%$ VC-R & 1.8667 & 0.683433 & 0.161036 & 0.3397 & -1.6170 \\
$25-75 \%$ VC-R & $100 \%$ VC & 1.1783 & 0.683433 & 0.785454 & -0.8300 & 1.4370 \\
& $50-50 \%$ VC-R & -0.5983 & 0.683433 & 0.377549 & 0.2497 & 3.3036 \\
& $75-25 \%$ VC-R & -0.6883 & 0.683433 & 0.167768 & -2.1167 & 0.7400 \\
$50-50 \%$ VC-R & $100 \%$ VC & 1,7767 & 0.683433 & 0.345023 & -2.0267 & 0.8300 \\
& $25-75 \%$ VC-R & 0.5983 & 0.683433 & 0.377549 & -0.2500 & 2.2067 \\
$75-25 \%$ VC-R & 75-25\% VC-R & -0.0900 & 0.683433 & 0.233733 & -3.3936 & -0.3397 \\
& $100 \%$ VC & 1.8667 & 0.683433 & 0.161036 & -3.3036 & -0.2497 \\
& $25-75 \%$ VC-R & 0.6883 & 0.683433 & 0.167768 & 0.2500 \\
\hline
\end{tabular}

recycled fiber proportion is equal with the virgin cotton, except for mix quantitative relations of $25 \%$ virgin cotton $75 \%$ recycled fiber, it reduced a little. The hairiness value of sample 3 (sa3) increased as the proportion of the recycled fiber increases. This is due to the difference in test methods of (sa1) and (sa3). The sample 1 (sa1) is the total length of protruded fibers along the yarn, while (sa3) is the count of fibers longer than $3 \mathrm{~mm}$. The increasing ratios of recycled 

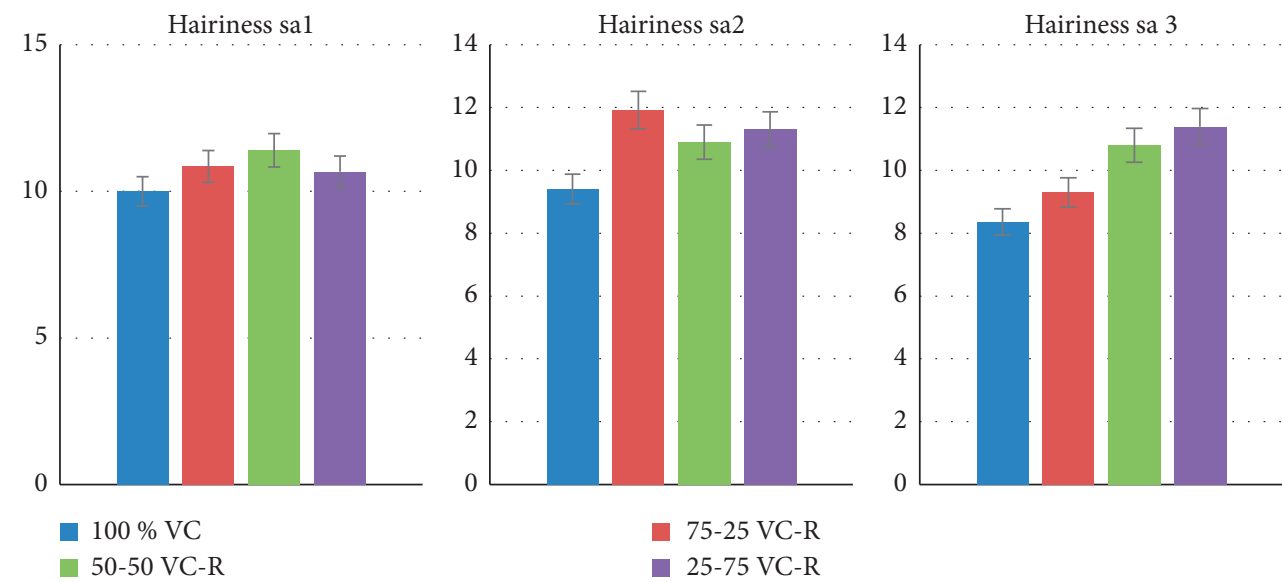

Figure 4: Hairiness (sa1, sa2, and sa3) values and 95\% confidence intervals

fibers means a high number of shorter fibers take place around the yarn surface, so that (sa1) and (sa2) values increase. It is also observed that reducing the total staple length reduces sa 3 values. The same conclusion was obtained from studies by R Gowthami et al. and Greg M. Peters $[15,16]$.

3.3. Effect of Imperfections. The effects of recycled fiber proportion on imperfections are shown in Figure 5. It illustrates that $100 \%$ virgin cotton yarn exhibits lower number of thin places, while $75-25 \%$ VC-R has higher amount of thin place. For the proportions of $75-25 \%$ and $50-50 \%$, neps percent is higher. The $25-75 \%$ ratio shows almost equal neps percent with $100 \%$ virgin cotton yarns. Except for the number of thin places of blend ratio (75\% virgin cotton and $25 \%$ recycled fiber), there was no significance difference between the other sample tests. The result of ratio $(75 \%$ virgin cotton and $25 \%$ recycled fiber) was related to rotor speed and not to blend proportion. The same findings were given by S. Sakthivel et al. and Dhanapriya et al. [17, 18].

3.4. Effect of Tensile and Elongation. Figure 6 shows breaking force and breaking elongation values. 100\% VC fiber yarns have the highest breaking force with the lowest elongation values. The effect of blending proportion (virgin cotton fiber and recycled fiber) is clearly shown in the figure as the proportion of the recycled fiber increases the strength, and elongation of the yarn is also increases. This is due to the increasing number of synthetic fibers like polyester that have strong breaking strength and elongation values. The experimental study was conducted by lhayat Getu Temesgen and S. Sakthivel et al. $[19,20]$.

3.5. Effect of Abrasion Resistance. The abrasion resistance results in terms of weight loss are analyzed in Figure 7 as the proportion of recycled fiber has a negative impact on the weight loss of the handloom fabric. Abrasion has a negative impact on the serviceability of textile fabrics; in this experimental study, the abrasion properties of plain and twill fabric designs produced from recycling blended yarns with different proportions are evaluated. The result indicates that except for the $100 \%$ virgin cotton fabrics, twill weaves which have lower interlacement increases the abrasion resistance by decreasing the weight loss. However, statistical analysis showed that there is no significant difference between the samples. From the results obtained, twill handloom sample fabrics have more resistance to abrasion than plain handloom fabrics from recycled fiber blends; this is due to the twill samples denser area, which reduces the short fibers contacted with abrader, and the samples in the opposite plain samples are loosely tightening; when abrader contacts the sample, it easily transfers the abrading force to entangled fiber masses from the yarns on the fabric and abrades to worn out them easily. The recycled fiber proportion shows no statistical difference between the samples. Most probable reason for this situation might be the decreasing contact area between abrader and the fibers that cause damage in yarn structure easily after the abrasive movements. The same results were obtained by Melese et al. and Rosace and Massafra [21, 22].

3.6. Effect of Pilling. Pilling is the tendency of fabric which creates a small entangled mass of fibers on their surface when they are subjected to rubbing force. The standards for pilling result of fabrics and number of pilling for each sample are illustrated in Figures 8 and 9, respectively. Figure 10 illustrates pilling grades of tested sample fabrics. Pilling is more related to protruding fiber ends; as the recycled fibers content increased, the pilling tendency of handloom fabric is much increased. Twill (25-75\% VC-RS) fabrics have the highest number of pilling values between all fabric types. The other point of view is that comparing fabrics produced from blended yarns show that up to $75 \%$ recycled fiber blended ratio does not cause a significant change on the pilling grade. The studies by F. Tabassum et al. and Fasika Abedom et al. $[23,24]$ stated that the plain handloom fabrics made from recycled fiber and virgin cotton blends have exhibited a higher pilling value, which means a few pilings, while twill handloom fabric has relatively small pilling values since there are more pilings during the test. 

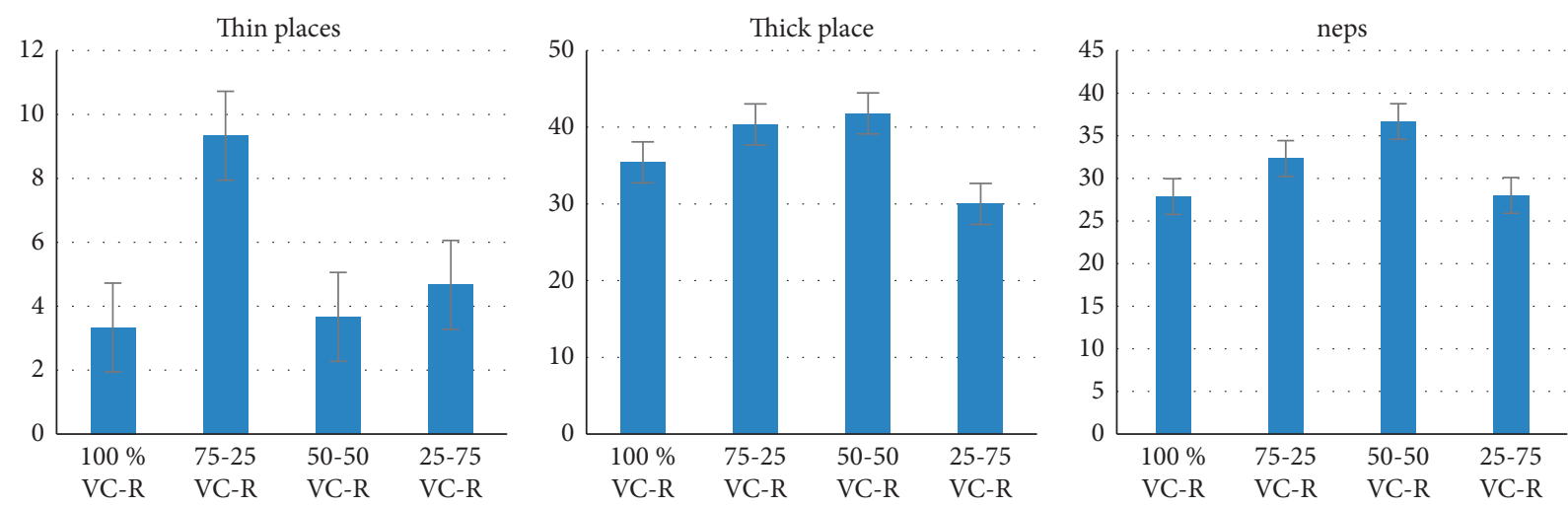

FIGURE 5: Imperfections (thin places, thick places, and neps) and 95\% confidence intervals.
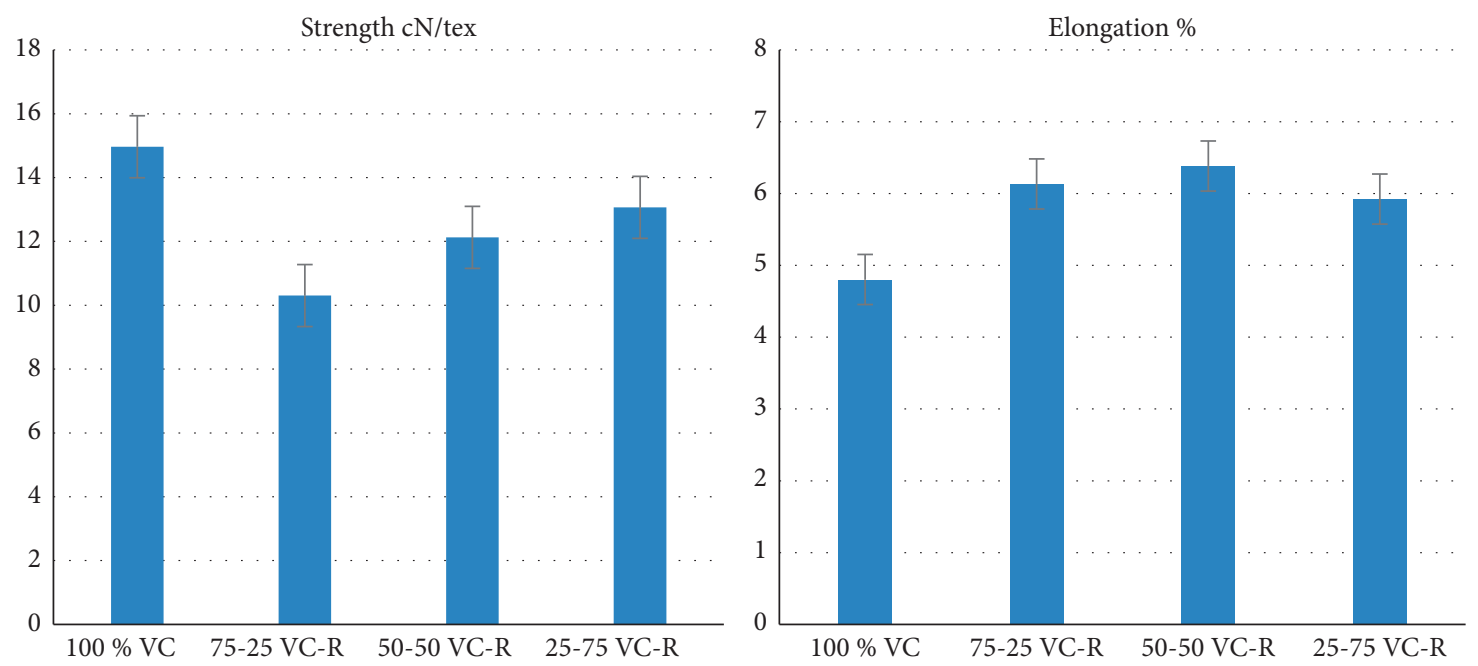

FIgURE 6: Breaking force (cN) and breaking elongation (\%) values and 95\% confidence interval.

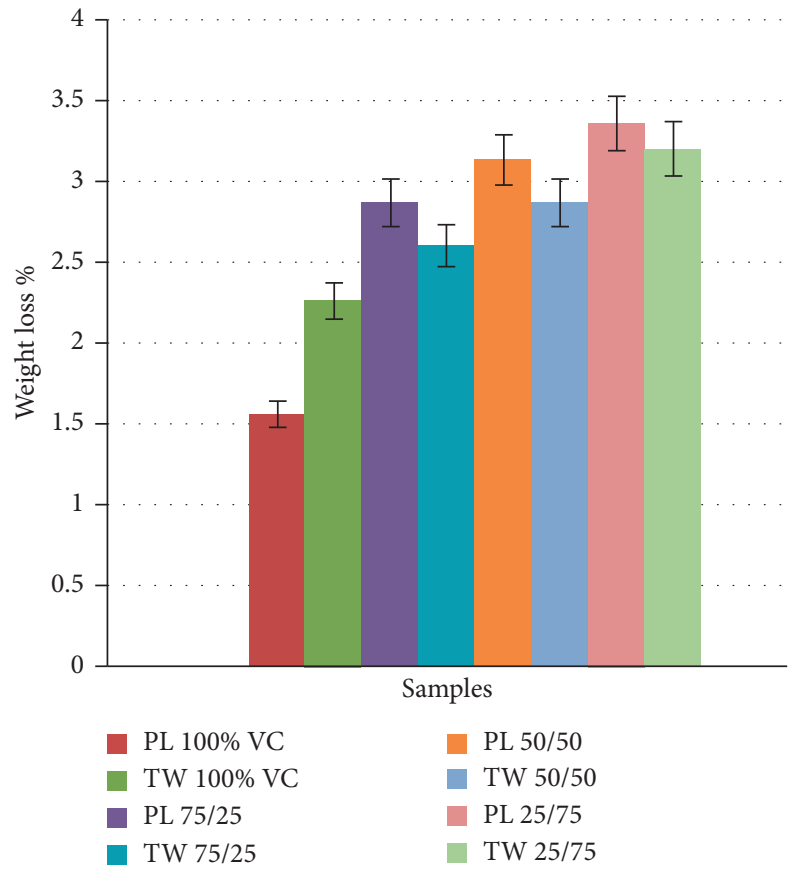

FIgURE 7: Weight loss (\%) of yarn developed fabric. 


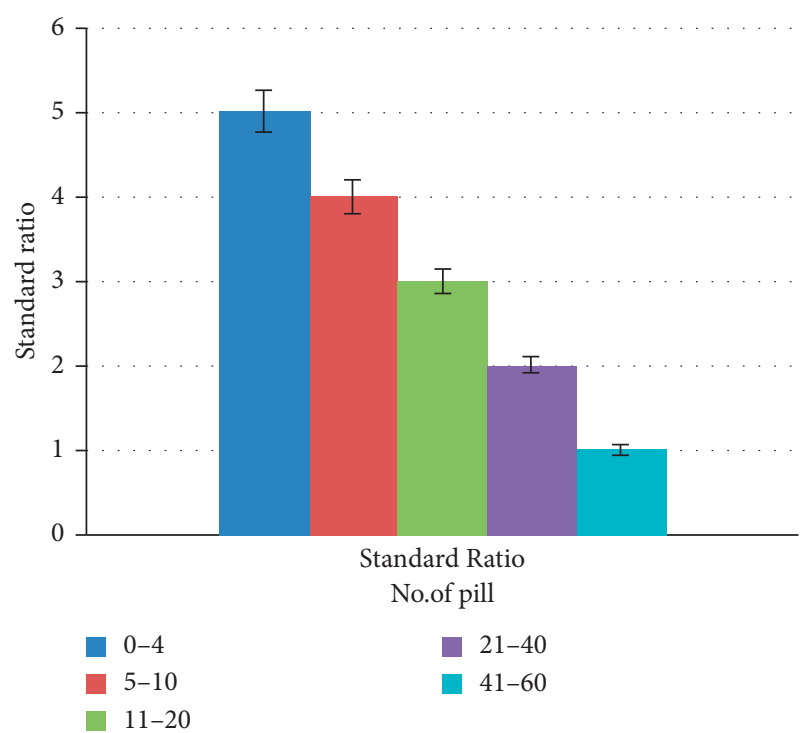

Figure 8: Standard ratio of the pilling test for woven fabrics.

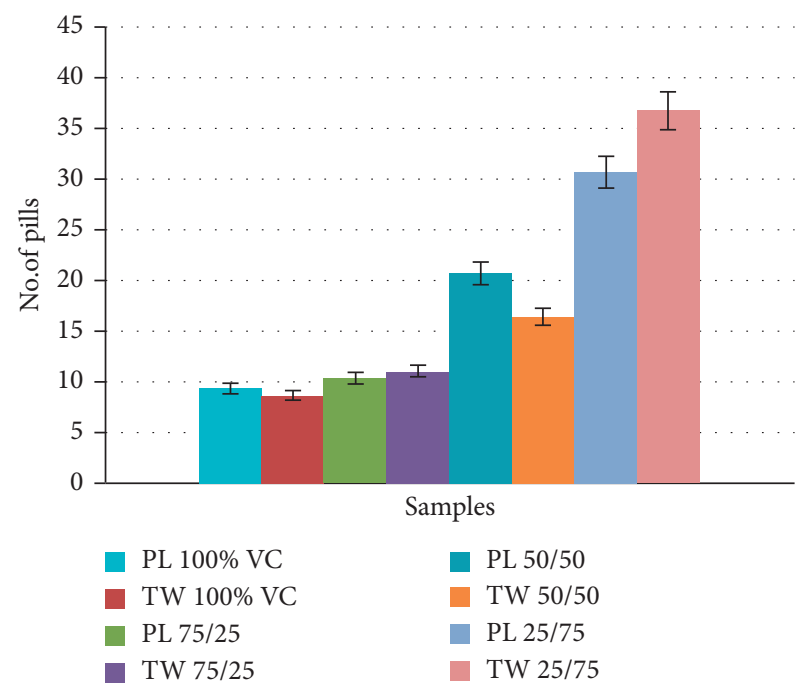

FIgURE 9: Number of pilling samples from developed fabrics.

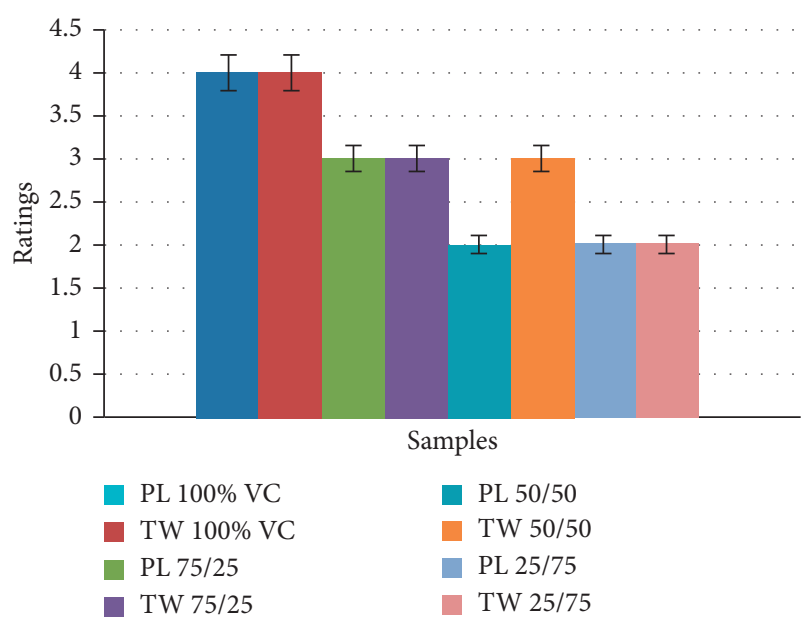

Figure 10: Rating of the prepared woven fabric samples pilling test.

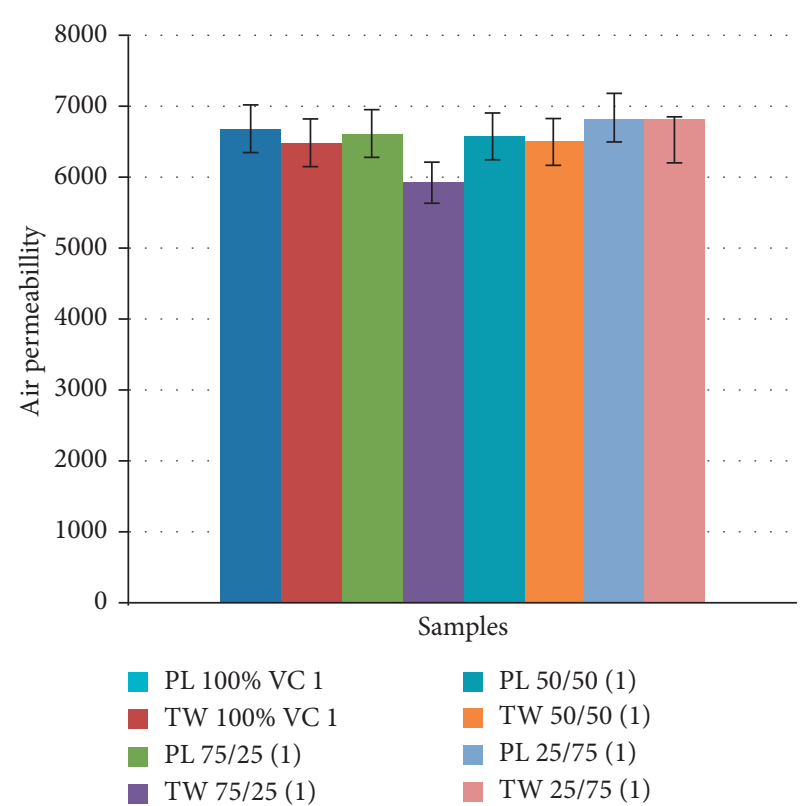

Figure 11: Air permeability $\left(1 / \mathrm{m}^{2} / \mathrm{s}\right)$ values and $95 \%$ confidence intervals.

3.7. Effect of Air Permeability. Figure 11 shows air permeability values for the produced fabrics. It is observed that the air permeability of hand-woven fabrics decreases by increasing the proportion of recycled fibers percent with no significant difference shown between samples. This situation is explained by the increasing amount of protruding fiber ends that decrease the fabric porosity. But, for blend ratio of $25 \%$ virgin cotton and $75 \%$ recycled fiber, the air permeability value is a little higher than the other samples; this is because of the high short fiber content; it is difficult to produce tight fabric, since hairy fibers alter smooth movement during the beat-up process of handloom operation. On the other hand, twill (TW) weave handloom fabric made from virgin cotton and recycled fiber blends has better resistance to airflow, while plain (PL) weaves are lower airflow resistance through the fabric surface. This is because twill handloom weaves are denser, while plain handloom fabrics are porous. The same conclusion was given by Rajib Al Mamun [25].

\section{Conclusions}

This study aimed to analyze the effects of recycled fiber usage on the properties of yarns and handloom fabrics used for home furnishing applications. For this purpose, OE-rotor yarns made of $100 \%$ virgin cotton and virgin cotton/recycled fibers blend at different proportions $(25 \%, 50 \%$, and $75 \%)$. Moreover, plain and twill fabrics are produced from all yarn types. Physical, structural, and mechanical properties of all yarn types such as unevenness, imperfections, hairiness, breaking force, and elongation were measured. Properties of fabrics such as pilling, abrasion resistance, and air permeability were also evaluated. Compared to virgin ones, recycled blended yarns tensile strength is better. But, with analysis of the data obtained from the sample test, no 
statistically significant difference is obtained, The ANOVAs analysis of the sample yarns show no significant difference in unevenness of yarns with $p$ value $(p=0.0743)$ at 95\% confidence level. With the analysis of produced handloom fabric, twill handloom sample fabrics have more resistance to abrasion than plain handloom fabrics from recycled fiber blends; fabrics produced from blended yarns show that up to $75 \%$ recycled fiber blended ratio does not cause a significant change on the pilling grade; for blend ratio of $25 \%$ virgin cotton and $75 \%$ recycled fiber, the air permeability value is little higher than the other samples. Because of the high short fiber content, it is difficult to produce tight fabric. According to the results of the data analysis of sample tests, it can be concluded that using up to $75 \%$ reclaimed fibers is more economical and environmentally friendly with no or small difference in physical, structural, and mechanical properties of yarns and fabrics produced. Handloom fabrics produced can suitably be used for home furnishing applications such as table covers, curtains, wall covers, and pillowcases.

\section{Data Availability}

The data were analyzed using one-way ANOVAs by using SAS software. The data used to support the findings of this study are included within the article.

\section{Conflicts of Interest}

The authors declare that they have no conflicts of interest.

\section{References}

[1] Y. K. Kim and A. F. Lewis, Recycling and Reuse of Mixed-Fiber Fabric Remnants, UMass Lowell, Chelsea Center for Recycling and Economic Development, Lowell, MA, USA, 2012.

[2] S. Rani and Z. Jamal, "Recycling of textiles waste for environmental protection," International Journal of Home Science, vol. 4, no. 1, pp. 164-168, 2018.

[3] S. Sakthivel and S. al, "Development of needle-punched nonwoven fabrics from reclaimed fibers for air filtration applications," Journal of Engineered Fiber and Fabric, vol. 9, no. 1, 2014.

[4] S. Adanur and F. Jing Qi, "Property analysis of denim fabrics made on air-jet weaving machine Part II," Textile Research Journal, vol. 78, no. 1, pp. 10-20, 2008.

[5] T. Ramachandran and S. Sakthivel, "Thermal conductivity of non-woven materials using reclaimed fibers," International Journal of Engineering Research and Applications (IJERA), vol. 2, no. 3, pp. 2983-2987, 2012.

[6] S. S. Ahmad, I. M. M. Mulyadi, N. Ibrahim, and A. R. Othman, "The application of recycled textile and innovative spatial design strategies for a recycling centre exhibition space," Procedia - Social and Behavioral Sciences, vol. 234, pp. 525535, 2016.

[7] S. Sakthivel and B. Senthil kumar, "Studies on influence of bonding methods on sound absorption characteristic of polyester/cotton recycled nonwoven fabric," Journal of Applied Acoustics, vol. 174, Article ID 107749, 2021.

[8] S. Sakthivel, S. Senthil Kumar, B. Melese et al., "Development of nonwoven composites from recycled cotton/polyester apparel waste materials for sound absorbing and insulating properties," Journal of Applied Acoustic, vol. 180, Article ID 108126, 2021.

[9] E. Pinheiro and A. de Francisco, "Management and characterization of textile solid waste in a local productive arrangement," Fibres and Textiles in Eastern Europe, vol. 24, no. 118, pp. 8-13, 2016.

[10] S. Sakthivel, B. Melese, A. Edae, F. Abedom, S. Mekonnen, and E. Solomon, "Garment waste recycled cotton/polyester thermal and acoustic properties of air-laid nonwovens," Advances in Materials Science and Engineering, vol. 2020, Article ID 8304525, 8 pages, 2020.

[11] S. Sakthivel, F. A. Tesfamicael, S. Mekonnen et al., "Recycled cotton/polyester and polypropylene nonwoven hybrid composite materials for house hold applications," Journal of the Textile Institute, vol. 112, pp. 1-9, 2021.

[12] A. Ahmad, "Waste management of textiles: a solution to the environmental pollution," Int.J.Curr.Microbiol.App.Sci, vol. 3, no. 7, pp. 780-787, 2014.

[13] R. Gupta, "Sustainable transformation in modest fashion through "RPET technology" and "dry-dye" process, using recycled PET plastic," International Journal of Recent Technology and Engineering, vol. 8, no. 3, pp. 5415-5421, 2019.

[14] R. Chandanu, "Development of technical textiles for automotive applications using reclaimed fibers," Man Made Textiles in India, vol. 40, no. 6, pp. p210-213, 2012.

[15] S. Sakthivel, T. Ramachandran, R. Gowthami et al., "Source \& effective utilization of textile waste in Tirupur," Indian Textile Journal, vol. 4, no. 2013, Article ID 22341374, 2012.

[16] G. M. Peters, G. Sandin, and B. Spak, "Environmental prospects for mixed textile recycling in Sweden," ACS Sustainable Chemistry \& Engineering, vol. 7, no. 13, pp. 1168211690, 2019.

[17] S. Sakthivel, T. Ramachandran, G. Archana, J. J. Ezhilanban, and V. M. S. Sivajith Kumar, "Sustainable nonwoven composites for automotive application using reclaimed fiber," International Journal of Engineering Research and Development e-ISSN, vol. 4, no. 7, pp. 30-44, 2012.

[18] S. Sakthivel, S. Senthil Kumar, N. Mekala, and G. Dhanapriya, "Development of sound absorbing recycled nonwoven composite materials," in Proceedings of the 2nd International Conference on Materials, Manufacturing and Machining for Industry 4.0 (ICMMM-2020), Tamil Nadu, India, October 2021.

[19] S. Sakthivel, S. Senthil Kumar, S. Mekonnen, and E. Solomon, "Thermal and sound insulation properties of recycled cotton/ polyester chemical bonded nonwovens," Journal of Engineered Fibers and Fabrics, vol. 15, 2020.

[20] A. G. Temesgen, "The art of hand weaving textiles and crafting on socio-ultural values in Ethiopian (review)," International Journal of Advanced Multidisciplinary Research, vol. 5, no. 12, pp. 59-67, 2018.

[21] S. Sakthivel, S. Senthil Kumar, and B. Melese, "Sound-absorbing recycled cotton/polyester thermal bonded nonwovens," Journal of the Textile institute, vol. 29, pp. 1-8, 2020.

[22] G. Rosace and M. R. Massafra, "Marking of cellulose yarn by vinyl monomer grafting," Textile Research Journal, vol. 78, no. 1 , pp. 28-36, 2008.

[23] F. Tabassum, "Garments waste recycling in dhaka: a case study of mirpur area," in Proceedings of the Waste Safe 2017-5th International Conference on Solid Waste Management in South Asian Countries, Khulna, Bangladesh, February 2017.

[24] F. Abedom, S. Sakthivel, D. Asfaw, B. Melese, E. Solomon, and S. Senthil Kumar, "Development of natural fiber hybrid composites using sugarcane bagasse and bamboo charcoal for 
automotive thermal insulation materials," Journal of Advances in Materials Science and Engineering, vol. 2021, Article ID 2508840, 10 pages, 2021.

[25] R. A. Mamun, M. R. Repon, M. T. Islam, and K. Z. M. A. Motaleb, "Promising effect of processing parameters on yarn properties in rotor spinning," Manufacturing Science and Technology, vol. 4, no. 1, pp. 11-15, 2017. 